EGU2020-17416

https://doi.org/10.5194/egusphere-egu2020-17416

EGU General Assembly 2020

(c) Author(s) 2020. This work is distributed under

the Creative Commons Attribution 4.0 License.

\title{
Siberian Arctic inland waters emit mostly contemporary carbon
}

\author{
Joshua Dean ${ }^{1,2}$, Ove Meisel ${ }^{2}$, Melanie Martyn Roscoe ${ }^{2}$, Luca Belelli Marchesini ${ }^{3}$, Mark Garnett ${ }^{4}$, \\ Henk Lenderink ${ }^{2}$, Richard van Logtestijn ${ }^{2}$, Alberto Borges ${ }^{5}$, Steven Bouillon ${ }^{6}$, Thibault Lambert ${ }^{5}$, \\ Thomas Röckmann ${ }^{7}$, Trofim Maximov ${ }^{8}$, Roman Petrov ${ }^{8}$, Sergei Karsanaev ${ }^{8}$, Rien Aerts ${ }^{2}$, Jacobus van \\ Huissteden ${ }^{2}$, Jorien Vonk ${ }^{2}$, and Han Dolman ${ }^{2}$ \\ ${ }^{1}$ School of Environmental Sciences, University of Liverpool, Liverpool, UK \\ ${ }^{2}$ Vrije Universiteit Amsterdam, Amsterdam, the Netherlands \\ ${ }^{3}$ Department of Sustainable Agro-ecosystems and Bioresources, Research and Innovation Centre, Fondazione Edmund \\ Mach, San Michele all'Adige, Italy \\ ${ }^{4}$ Natural Environment Research Council Radiocarbon Facility, East Kilbride, United Kingdom \\ ${ }^{5}$ Chemical Oceanography Unit, University of Liège, Liège, Belgium \\ ${ }^{6}$ Department of Earth and Environmental Science, Katholieke Universiteit Leuven, Leuven, Belgium \\ ${ }^{7}$ Institute for Marine and Atmospheric Research, Utrecht University, Utrecht, the Netherlands \\ ${ }^{8}$ Institute for Biological Problems of the Cryolithozone, Siberian Branch Russian Academy of Sciences, Yakutsk, Russia
}

Inland waters (rivers, lakes and ponds) are important conduits for the emission of terrestrial carbon in Arctic permafrost landscapes. These emissions are driven by turnover of contemporary terrestrial carbon and additional "pre-aged" (Holocene and late-Pleistocene) carbon released from thawing permafrost soils, but the magnitude of these source contributions to total inland water carbon fluxes remains unknown. Here we present unique simultaneous radiocarbon age measurements of inland water $\mathrm{CO}_{2}, \mathrm{CH}_{4}$ and dissolved and particulate organic carbon in northeast Siberia during summer. We show that $>80 \%$ of total inland water carbon emissions were contemporary in age, but that pre-aged carbon contributed $>50 \%$ at sites strongly affected by permafrost thaw. $\mathrm{CO}_{2}$ and $\mathrm{CH}_{4}$ were younger than dissolved and particulate organic carbon, suggesting emissions were primarily fuelled by contemporary carbon decomposition. The study region was a net carbon sink (-876.9 $\pm 136.4 \mathrm{Mg} \mathrm{C}$ for 25 July to 17 August), but inland waters were a source of contemporary (16.8 $\mathrm{Mg} \mathrm{C}$ ) and pre-aged (3.7 Mg C) emissions that respectively offset $1.9 \pm 1.2 \%$ and $0.4 \pm 0.3 \%$ of $\mathrm{CO}_{2}$ uptake by tundra ( $\square 897 \pm 115 \mathrm{Mg} \mathrm{C}$ ). Our findings reveal that inland water carbon emissions from permafrost landscapes may be more sensitive to changes in contemporary carbon turnover than the release of pre-aged carbon from thawing permafrost. 